\title{
Vein of Galen Aneurysmal Malformations in Pediatric Patients Submitted to Endovascular Treatment: Report of 3 Cases
}

\section{Malformações aneurismáticas da veia de Galeno em pacientes pediátricos submetidos a tratamento endovascular: Relato de 3 casos}

\author{
Amanda Cristina Zimmermann ${ }^{10}$ Bernardo Przysiezny ${ }^{10}$ Evelyn Della Giustina ${ }^{1,2}$ (1) \\ Guilherme Voltolini Staedele ${ }^{10}$ Leandro José Haas ${ }^{1,3}$ Letícia Saori Tutida10 \\ Liz Caroline de Oliveira Camilo ${ }^{10}$
}

${ }^{1}$ Blumenau Regional University Foundation, Blumenau, SC, Brazil

2 Santo Antonio Hospital, Blumenau, SC, Brazil

${ }^{3}$ Department of Interventional Neuroradiology, Hospital Santa Isabel,

Blumenau, SC, Brazil

Arq Bras Neurocir 2021;40(4):e374-e379.

\author{
Address for correspondence Amanda Cristina Zimmermann, MD, Rua \\ Petrolândia, 112, Água Verde, Blumenau, SC, 89036-620, Brazil \\ (e-mail: amanda.zimmermann@hotmail.com).
}

\author{
Abstract \\ Keywords \\ - arteriovenous \\ malformations \\ - intracranial aneurysm \\ - vein of Galen \\ - endovascular \\ procedures \\ - pediatrics \\ - neurosurgery
}

Objective To report three cases of vein of Galen aneurysmal malformation (VGAM) in pediatric patients treated at the hemodynamics lab of Hospital Santa Isabel (HSI) in Blumenau, state of Santa Catarina, Brazil, from 2006 to 2020. Clinical presentation, endovascular treatment, and postprocedure evolution to date are included.

Case description Three children aged 5 to 12 months with cardiac, respiratory, or neurological damage in the neonatal stage, were referred to the neurosurgery service and diagnosed with VGAM. The three patients underwent endovascular embolization of the malformation, with different clinical evolution throughout outpatient follow-up. Conclusion Vein of Galen aneurysmal malformations are uncommon vascular abnormalities that, until the advent of endovascular embolization, were associated with high morbidity and mortality rates. Its prognosis is linked with initial clinic, early diagnosis, and timely surgical correction.

This study took place at FURB and Santa Isabel Hospital at Blumenau, Santa Catarina- Brazil.

received

August 16, 2020

accepted

February 22, 2021

published online

August 11, 2021
DOI https://doi.org/ 10.1055/s-0041-1730372. ISSN 0103-5355.

\footnotetext{
(c) 2021. Sociedade Brasileira de Neurocirurgia. All rights reserved. This is an open access article published by Thieme under the terms of the Creative Commons Attribution-NonDerivative-NonCommercial-License, permitting copying and reproduction so long as the original work is given appropriate credit. Contents may not be used for commercial purposes, or adapted, remixed, transformed or built upon. (https://creativecommons.org/ licenses/by-nc-nd/4.0/) Thieme Revinter Publicações Ltda., Rua do Matoso 170, Rio de Janeiro, RJ, CEP 20270-135, Brazil
} 


\section{Resumo}

Palavras-chave

- malformações arteriovenosas

- aneurisma intracraniano

- veia de Galeno

- procedimentos endovasculares

- pediatria

- neurocirurgia
Objetivo Relatar três casos de malformação aneurismática da veia de Galeno (MAVG) em faixa etária pediátrica atendidos no setor de hemodinâmica do Hospital Santa Isabel (HSI) de Blumenau, SC no período de 2006 a 2020, relatando a apresentação clínica, o tratamento endovascular bem como a evolução pós-procedimento até o presente ano. Descrição do caso Os relatos descrevem 3 crianças entre 5 e 12 meses de idade que apresentaram alterações cardíacas, respiratórias ou neurológicas no período neonatal, encaminhadas para o serviço de neurocirurgia e diagnosticadas com MAVG. Os três casos foram submetidos à embolização endovascular da malformação, diferindo na evolução clínica ao longo do seguimento ambulatorial.

Conclusão As MAVGs são anomalias vasculares incomuns de elevada taxa de morbimortalidade até o advento da embolização endovascular. O seu prognóstico está ligado à clínica inicial, ao precoce diagnóstico e à correção cirúrgica no momento adequado.

\section{Introduction}

Vein of Galen aneurysmal malformation (VGAM) is a rare vascular anomaly occurring during the embryonic stage that accounts for $\sim 30 \%$ of pediatric vascular diseases and $1 \%$ of all cerebrovascular malformations. ${ }^{1}$ It is characterized by multiple arteriovenous fistulas (AVFs) between arterial branches and a median prosencephalic vein (MPV), the embryonic precursor of the vein of Galen (VG). ${ }^{2}$ It is believed to occur between the 6th and 11th week of fetal formation. ${ }^{3}$ Genetic predisposition and association has been reported, such as RASA 1 mutation. ${ }^{4}$ Clinical manifestations include cardiac alteration such as high output heart failure, and neurological ones due to venous congestion and abnormal cerebrospinal fluid (CSF) flow. ${ }^{5}$

Despite its low incidence, it is an important morbidity and mortality factor in newborn babies (NBs) and can also be diagnosed in infants, children and, less frequently, adults. ${ }^{2}$ Differences in its clinical evolution, angioarchitecture, and effects on systemic physiology make its approach complex and challenging. ${ }^{5}$ In the absence of treatment, these malformations are fatal in almost $100 \%$ of the cases due to multiple organ failure in the first weeks of life or to complications of hydrocephalus in the first years of life. ${ }^{6}$

Lasjaunias et al. differentiate malformations involving dilatation of the VG from the MPV, this latter being true VGAM. ${ }^{5}$ Two types of angioarchitecture are described for true VGAM: choroidal - the most common type and with worse prognosis - and mural. Yasargil also proposed a classification dividing these malformations into four types. He distinguished the malformations with pure AVF (types IIII) from the arteriovenous malformations with drainage to the VG (type IV); the author also takes into account the exact origin of the feeding arteries in each type. ${ }^{3}$

Advances in neuroimaging devices and endovascular access materials have enabled the development of effective techniques for VGAM embolization with a positive impact on the prognosis of these patients. Coils or Histoacryl (Laboratórios B. Braun S. A., São Gonçalo, Rio de Janeiro, Brazil)
(NBCA- N-Butilcianoacrylate) can be used and the endovascular procedure is usually performed through the arterial pathway. ${ }^{1}$ Previous studies showed that the transvenous approach is associated with a higher rate of postembolization hemorrhage compared with the transarterial approach. Ventriculoperitoneal shunting (VPS) is an alternative that reverses the pressure gradient from the subarachnoid space to the superior sagittal sinus. In clinically stable patients, it is preferable to delay embolization until 5 to 6 months of the age, ${ }^{4}$ although some cases require emergency intervention in the NB. ${ }^{7}$ At this age, aggressive endovascular embolization reduces hydrodynamic pressure and allows to reserve CSF diversion procedure for refractory cases. ${ }^{4}$

In most cases, multiple interventions are required, ${ }^{1}$ from clinical stabilization to complete resolution of the malformation. During the staged treatment by endovascular embolization, a new parenchymal angiogenetic network of vessels can be developed, needing a new approach for obliteration of the dilated venous sac. Dural feeders to the VGAM may be observed on initial or follow-up angiogram during staged embolization, which happens in $\sim 30 \%$ of cases. ${ }^{4}$

The objective of the current study is to present cases of VGAM treated at the hemodynamics lab of the Hospital Santa Isabel (HSI), Blumenau, SC, from 2006 to 2020, reporting the clinical history, diagnostic and therapeutic interventions, and each patient's evolution throughout the outpatient follow-up to date.

\section{Case Reports}

\section{Case 1}

A baby girl delivered at 38 weeks of gestation by cesarean section, $33 \mathrm{~cm}$ head circumference, Apgar score of 9 at 1 minute and 10 at 5 minutes. No gestational history. She required hospitalization for 18 days in a neonatal intensive care unit (ICU) and intermediate care unit (IMCU) due to heart failure and seizures. Diagnosis of congenital heart disease by echocardiography. At 3 months of age, a brain magnetic resonance imaging (MRI) showed right cerebral 
hemiatrophy and Galenic cerebral arteriovenous malformation (AVM). At 5 months of age, she underwent digital cerebral angiography, which showed a right thalamic, fistulous, choroidal type AVM with several afferences and venous drainage to the VG with significant associated dilatation, Yasargil type 4. Then, a transarterial endovascular embolization of the meningeal branch and two choroidal branches with direct afference to the AVM was performed with Histoacryl. The procedure was well tolerated and without complications.

At 7 months of age, the patient required a ventriculoperitoneal shunt (VPS) on the left side of the brain. At 13 months, she underwent control angiography, which detected a remnant of the Galenic fistulous AVM, involving all cerebral arteries, type 4 Yasargil, and was subjected to a new venous and arterial embolization with Histoacryl. At 2 years of age, a subdural hygroma was identified on a computed tomography (CT) image of the skull, which was followed by the placement of a VPS on the right side of the brain. She was on Depakene (Abbott Laboratórios do Brasil Ltda,, São Paulo, São Paulo Brazil). (Valproic Acid), Tegretol (Novartis Biociências S. A., São Paulo, São Paulo, Brazil) (Carbamazepine) and Rivotril (Produtos Roche Químicos e Farmacêuticos S. A., Rio de Janeiro, Rio de Janeiro, Brazil) (clonazepan), having achieved complete control of seizures at 6 months of age. At 4 years of age, she developed spasticity, dysphagia and delayed neuropsychomotor development, aphasia, and absence of ambulation. In the same year, she had a control cranial CT scan, which showed the persistence of non-hypertensive hydrocephalus, with intracranial calcifications.

During her 5th year of life, she had an improvement in her social and communication skills reported by family members and confirmed by medical evaluation, as she was able to say her name and interact by means of smiles and laughter. In subsequent consultations at 6,9 , and 10 years old, her symptoms remained unchanged. She had no new seizures and maintained good neurological stability. At 14 years and 6 months old, she still had tetraparesis and global spasticity, and had had a recent motor seizure. The patient was prescribed botulinum toxin, and Trileptal (Novartis Farma S.P.A., Naples, NA, Italy) (oxcarbazepine) was added to her anticonvulsants. The patient is stable and with no new complaints to date.

\section{Case 2}

A baby girl, born at term at 37 weeks by cesarean section, Apgar score 8 at 1 minute and 9 at 5 minutes, $35 \mathrm{~cm}$ head circumference, and heart murmur. She was referred to a neurosurgeon at 6 months and 18 days of age due to a venous protrusion in the open fontanelles, which had already been investigated by means of a skull CT. A family member brought a chest X-ray showing a cardiomegaly finding, an echocardiogram indicating heart failure, and a cranial CT showing VGAM. The child was pale, had prominent frontal veins, and was hypoactive on neurological examination. We decided to treat the venous malformation endovascularly.

At 7 months of age, on her preoperative evaluation, she had a $44 \mathrm{~cm}$ head circumference. Digital cerebral angiography revealed mural type VGAM, with afference to thin branches of the posteromedial choroidal artery and venous drainage to a giant aneurysm of the VG $-50 \times 40 \mathrm{~mm}$ (-Fig. 1: A-E). Subsequently, endovascular embolization of the VG aneurysm was performed by arterial and venous routes using platinum spirals (coils). During the embolization, the monitors did not show any changes, and the patient tolerated the procedure well. At 8 months, her evolution was good, she was sitting unsupported, active, had handgrip and plantar reflexes, and presented improved engorgement of facial vessels and cardiac symptoms. A control CT scan performed 1 month after the procedure showed a dilation of the bilateral frontal horns with no signs of intracranial hypertension (ICH).

At 14 months, a neurosurgery service in her hometown placed a VPS on the right side. At 15 months, she was referred to us because she had a right head tilt, left hemiparesis, $50 \mathrm{~cm}$ head circumference, and she was not crawling or sitting up. In the following month, a new digital cerebral angiography was performed, which showed the remainder of the VGAM, with residual aneurysm, measuring $30 \times 20 \mathrm{~mm}$, with coils inside it ( - Fig. 1: F-H). A new embolization was performed by arterial access through the posteromedial choroidal artery using Histoacryl, achieving complete occlusion. At 1 year and 5 months, her left subdural hematoma was drained. A month later, a skull MRI was performed, showing a small subdural residual collection, a functioning VPS on the right, and a cast of coils and Histoacryl inside the venous malformation.

In consultation at 2 years of age, she was active, could utter words, eat well, and walk with support, despite visual impairment with incomplete III nerve palsy on the left side. At the age of 3, she returned for a VPS review, whose valve was working. Her heart symptoms had improved without the use of medication, and she had no motor deficit or peculiarities in the neurological exam other than divergent strabismus. Her mother reported that she had started attending a dedicated school.

\section{Case 3}

A baby boy born at term by cesarean section, Apgar 7 at 1 minute, and 8 at 5 minutes. No adequate antenatal checkups in his hometown. In the neonatal period, he had congestive heart failure, respiratory failure, and hydrocephalus. State of convulsive illness. At 12 months of age, the patient was referred to us from a different neurosurgical service due to failure in a previous attempt for endovascular treatment of VGAM, diagnosed, along with hydrocephalus, by skull MRI.

A family member reported progressive head circumference increase associated with drowsiness and apathy. We placed a medium pressure VPS on the right side; two days postsurgery, the patient had significant respiratory distress. After performing an echocardiogram that showed mild heart failure, he needed to be transferred to a pediatric ICU.

A digital cerebral angiography was performed, which showed VGAM, with a giant VG aneurysm of $40 \times 30 \mathrm{~mm}$, with venous drainage to the sickle sinus, extremely dilated and engorged (-Fig. 2: A-E). At 14 months of age, he underwent his first session of endovascular treatment by arterial and venous routes, when platinum spirals (coils) were 


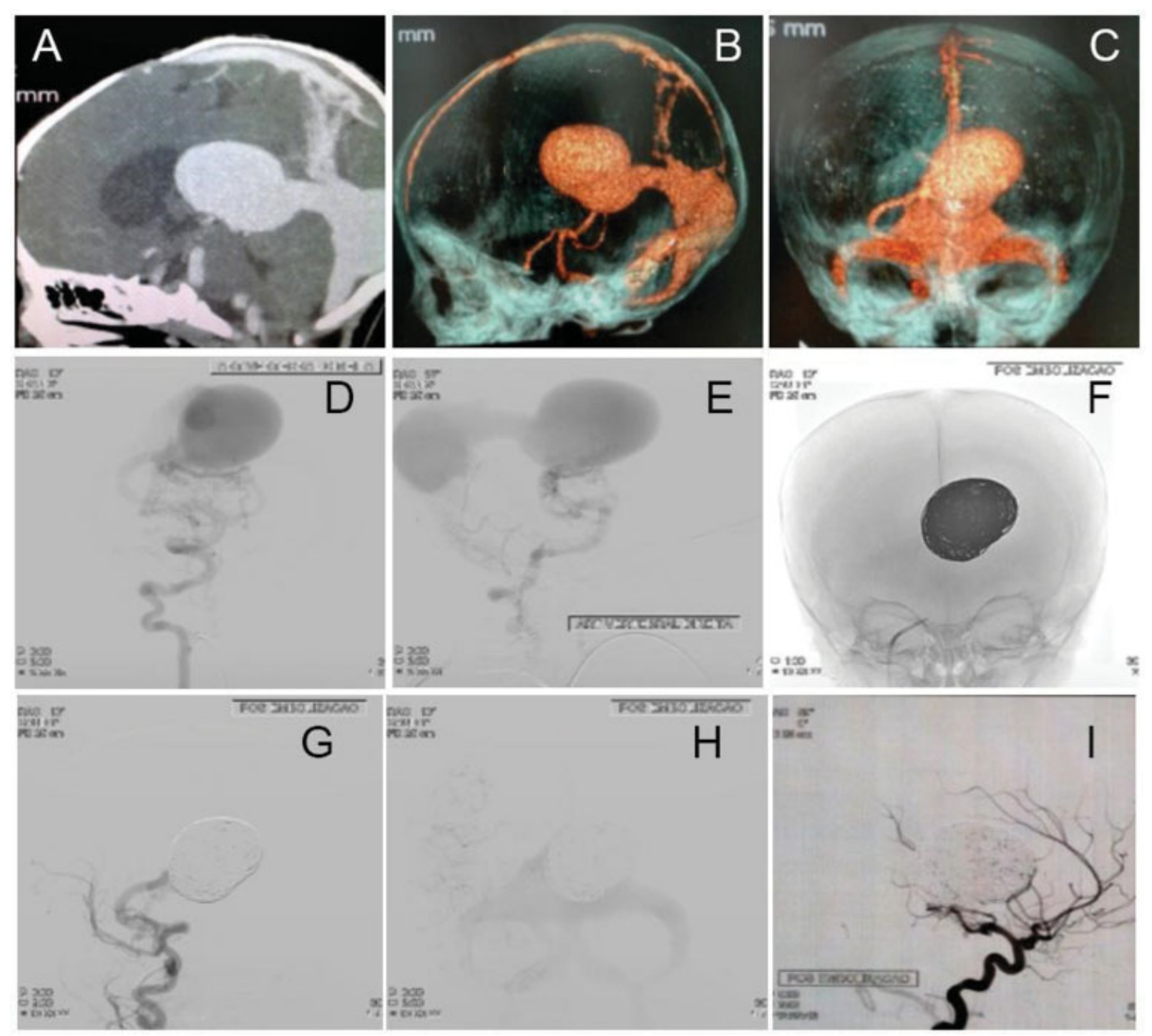

Fig. 1 Images of patient 2 exams. A: Cerebral angiotomography revealing a $50 \mathrm{~mm} \times 40 \mathrm{~mm}$ mural-type VGAM with afference to thin branches of the posteromedial choroidal artery and associated giant aneurysm; BC: Cerebral computed tomography angiography with 3D reconstruction, confirming a $50 \mathrm{~mm} \times 40 \mathrm{~mm}$ mural-type VGAM; IN: Arteriography of the right vertebral artery (presence of more pronounced tortuosity) showing VGAM mural type with afference through thin branches of the posteromedial choroidal artery and venous drainage to a giant vein of Galen aneurysm (arterial phase).; FH: Arteriography revealing VGAM occlusion after the 1st session of endovascular transarterial embolization with the use of coils; I: Arteriography revealing total VGAM occlusion after the 2nd session using Histoacryl (NBCA- N-Butylcyanoacrylate).

placed, achieving partial occlusion of the aneurysm (-Fig. 2: F-I). During embolization, monitors showed that the patient was undergoing alterations. It was decided to discontinue the procedure and schedule a new session. However, the patient developed aggressive infectious complications pneumonia - progressing to sepsis and death.

\section{Discussion}

Hydrodynamic and CSF disorder explain the pathophysiology of VGAM presentation. The absorption of the CSF occurs mostly through the arachnoid granulations in the matured brain, driven by the sump effect due to negative pressure in the dural sinuses. The high-flow shunts cause increased pressure in the venous sinus, resulting in CSF malabsorption. Additional factors, such pulmonary hypertension and skull base maturation, can aggravate the condition. Venous ischemia of the brain over time induces bilateral subcortical white matter calcification and atrophy of brain, manifested by psychomotor developmental delay and seizures. ${ }^{4}$

The three patients described above are cases of VGAM diagnosed in the postnatal period, considerably different from each other in neonatal clinical presentation and postprocedure evolution. The first patient had unfavorable initial clinical presentation of congestive heart failure and seizures, requiring intensive care unit (ICU) admission. Case 2 describes a patient with no neurological or respiratory alterations in the neonatal period, with isolated impairment of cardiac function. The third one reports a critical NB with congestive heart failure, respiratory failure, a state of convulsive illness and hydrocephalus, which progressed to coma. In all cases, endovascular treatment was performed, 


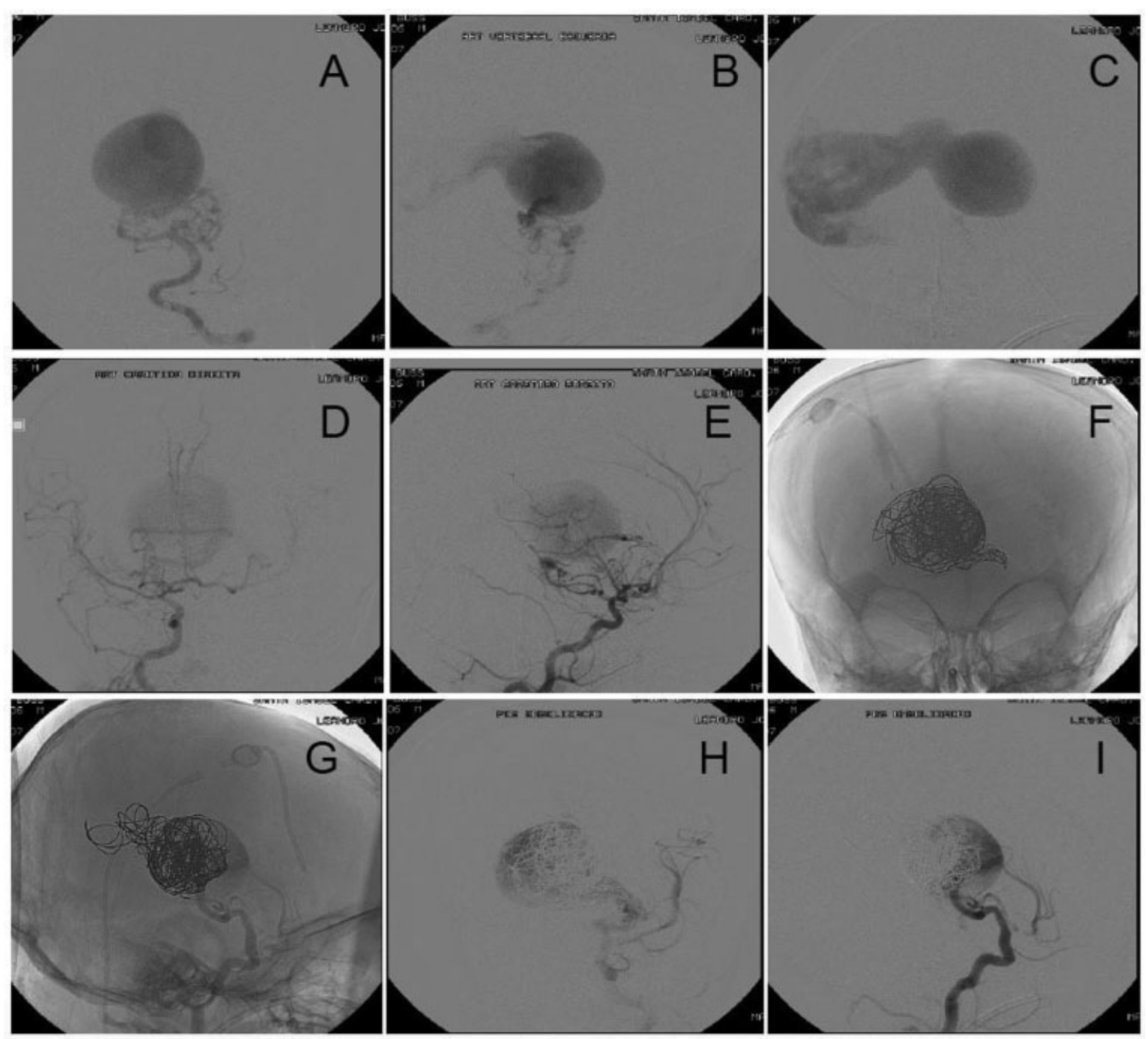

Fig. 2 Images of patient 3 exams. A: Arteriography via the left Vertebral Artery revealing a $40 \mathrm{~mm} \times 30 \mathrm{~mm}$ VGAM of the choroidal type (arterial phase: A and B; venous phase: C); D-E: Arteriography via the right internal carotid artery showing $40 \mathrm{~mm} \times 30 \mathrm{~mm}$ choroidal VGAM (arterial phase); F-I: Arteriography after endovascular transarterial embolization revealing coils inside the aneurysm where aneurysm thrombosis and slow venous return are observed. Partial exclusion.

with the first malformation embolization session taking place between 5 and 14 months of age.

Endovascular treatment is the conduct of choice for VGAM, since conventional surgical alternative is associated with significant mortality. In the long term, it is ultimately expected to achieve total obliteration of the malformation, with consequent normal neurological development and absence of deficits, which usually requires several stages and yet it is not always feasible. The immediate therapeutic goal at each stage varies according to the patient's clinical presentation and age. In NBs, the goal is to relieve congestive heart failure, while in infants and early childhood it is to restore the hydro-venous balance allowing normal brain development. ${ }^{4}$

The prognosis for NBs with VGAM can be established based on the Bicêtre score for the evaluation of the newborn, which is based on clinical and radiological findings related to cardiac, respiratory, neurological, hepatic, and renal function. A score lower than 8 suggests a near-fatal prognosis, and no treatment is proposed. A score between 8 and 12 indicates the need for urgent embolization, and between 12 and 21, a more stable condition, which allows the endovascular treatment to be postponed for 5 months, the age at which it is best tolerated. ${ }^{8}$ We can give the $1 \mathrm{st}$ patient a Bicêtre score of 14 , the 2 nd, of 20 , and the $3 r d$ a score of 10 , which, indeed, is consistent with the outcome in each case. It was not possible to offer patient 3 an early treatment, since he was referred to the neurosurgery service at 1 year of age.

Regarding surgical intervention, in the 1st case, a single surgical approach was performed at 5 months by arterial route with NBCA, in which complete occlusion of the malformation was not achieved. For patient 2, the 1 st embolization performed at 7 months by arterial and venous routes with platinum coils (coils) did not achieve total occlusion of the VGAM; this was achieved in the 2nd approach with Histoacryl, by arterial access, at 1 year and 4 months. Patient 
3 was treated at 1 year and 3 months by transarterial embolization with platinum coils, achieving partial aneurysm occlusion; subsequent interventions were not possible because the patient died.

Two hundred and thirty-three patients out of a series (published by Lasjaunias et al.) of 317 individuals with VGA underwent endovascular embolization; their overall mortality was $10.6 \%$, being higher in NBs (52\%). Of the survivors, $74 \%$ had no neurological sequelae during follow-up, $15.6 \%$ had moderate neuropsychomotor retardation, and $10.4 \%$ had severe retardation. ${ }^{9}$ In the present study, the patient who died had presumably unfavorable prognosis due to clinical presentation and delayed referral. The 1 st surviving patient was followed up until the age of 14 and progressed with motor impairment, delayed neurodevelopment, and seizures well-controlled with medication. As to the 2nd patient, who was followed up until 3 years of age, he had no neurological alterations other than visual impairment, with good overall evolution.

The natural history of VGAM has been modified by endovascular techniques, which are the first choice of treatment, highly effective and safe when performed at the right time and with the appropriate indications. ${ }^{10}$ Recent studies report that endovascular treatment of VGAM in neonates can reduce the severity of pulmonary hypertension and intracranial hydrodynamic pressure, thus lowering the risk for developing critical heart failure, multiple organ failure and ventricular enlargement. ${ }^{11}$ However, some authors concluded that the presence of normal deep venous drainage into the venous sac of the VGAM, excessive embolization of the venous outflow, treatment of more proximal fistulae before treating distal fistulae, and the use of larger microcatheters in neonates can contribute to an unexpected outcome. ${ }^{12}$ It is important to consider that despite the technological evolution leading to early diagnosis and more favorable treatments, the prognosis of these patients remains associated with their clinical conditions at birth. $^{10}$

\section{Conflict of Interests}

The authors have no conflict of interests to declare.

\section{References}

1 Sivasankar R, Limaye US, Wuppalapati S, Shrivastava M. Endovascular Management of Vein of Galen Aneurysmal Malformations: A Retrospective Analysis over a 15-Year Period. J Vasc Interv Neurol 2019;10(03):23-29

2 daSilva JFC, Lacerda DAM, Machado GHS, Nihi MA, João PRD. Malformação Arteriovenosa da Veia de Galeno no Recém- Nascido. Relato de Caso e Revisão de Literatura. Jornal Brasileiro de Neurocirurgia. 2017;27(03):231-239Brazilian.

3 Mortazavi MM, Griessenauer CJ, Foreman P, et al. Vein of Galen aneurysmal malformations: critical analysis of the literature with proposal of a new classification system. J Neurosurg Pediatr 2013; 12(03):293-306

4 Berenstein A, Paramasivam S, Sorscher M, Molofsky W, Meila D, Ghatan S. Vein of Galen Aneurysmal Malformation: Advances in Management and Endovascular treatment. Neurosurgery 2019; $84(02): 469-478$

5 Siqueira MG. Tratado de Neurocirurgia. Brasil: Manole; 2015

6 Taffin H, Maurey H, Ozanne A, et al. Long-term outcome of vein of Galen malformation. Dev Med Child Neurol 2019:1-6

7 Yan J, Wen J, Gopaul R, Zhang CY, Xiao SW. Outcome and complications of endovascular embolization for vein of Galen malformations: a systematic review and meta-analysis. J Neurosurg 2015;123(04):872-890

8 Spazzapan P, Milosevic Z, Velnar T. Vein of Galen aneurismal malformations - clinical characteristics, treatment and presentation: Three cases report. World J Clin Cases 2019;7(07):855-862

9 Lasjaunias PL, Chng SM, Sachet M, Alvarez H, Rodesch G, GarciaMonaco R. The management of vein of Galen aneurysmal malformations. Neurosurgery 2006;59(05, Suppl 3):S184-S194, discussion S3-S13

10 Lasjaunias P. Vascular diseases in neonates, infants and children. New York: Springer-Verlag; 1997

11 Seleznev P, Orlov K, Berestov V, et al. Outcomes of endovascular treatment of vein of galen aneurysmal malformation in neonates. J Neurointerv Surg 2020;12:A20-A21

12 Bhatia K, Mendes Pereira V, Krings T, et al. Factors contributing to major neurological complication from Vein of Galen malformation embolization. JAMA Neurol 2020;77(08):992-999 